\title{
REVIEW XVIII.
}

\section{A T'reatise on Diseases of the Joints. By Richard Barwell, F.R.C.S., Assistant-Surgeon to Charing-cross Hospital, \&c.-London, 1861. pp. 469.}

The fifth and last edition of Sir Benjamin Brodie's well-known and valuable work appeared in 1850 , a work which, admirable as it was, was not sufficiently exhaustive to deserve the name of a treatise. Its title, 'Pathological and Surgical Observations on the Diseases of the Joints,' most accurately represented its nature; it was a record af the experience and researches of a very acute, experienced, and cautious observer. On the other hand, it gave scarcely any account of the numerous investigations published by English, and none whatever of those by Foreign authors; and yet even twelve years ago considerable advance had been malle towards a more exact knowledge of the minute anatomy of the healthy tissues; pathological anatomy had been developed by Laennec, Rokitansky, Lebert, \&c. ; and, lastly, the introduction of subcutaneous tenotomy by Stromeyer had given a great impulse to the study of deformities, of which so many resulted from joint-disease.

From that to the present time there has appeared in our language no work that could be considered as at all a satisfactory exposition of the existing state of our knowledge of this subject, and thus there could be no question that a full and systematic treatise was urgently demanded, one to which both the scientific student and the busy pratitioner could have recourse in time of need. But before proceeding to examine how far Mr. Barwell has succeeded in supplying this desideratum, we must not forget to mention that in 1845 Bonnet published his very valuable treatise, and in 18.54 there appeared the 'Traité des Tumeurs Blanches des Articulations,' by Dr. J. Crocq, a work to which we have often had occasion to refer, and which we are sorry to find unquoted by Mr. Barwell, for we think his work would have gained in more ways than one had he perused it.

A glance at the table of contents suggests the remark, that as the author gives a chapter on physiological anatomy, he might very well have collected his observations on their pathological anatomy and phy. siology into another, for by such an arrangement many of the succeeding chapters would have gained in unity and clearness. Nor can we see why his disquisitions on rheumatism, gont, scrofula, should be scattered in different portions; their only value in this work is to show the etiology of joint-diseases, and they should accordingly be placed together in a chapter specially devoted to that subject. Chapter III., on acute rheumatism, is rather oddly separated by two chapters-one on pyarthrosis, the other on strumous synovitis-from the sixtb, which is devoted to rheumatic synovitis. This plan is very

* The only work by any contic outal writer mentioned is Bichat's 'Traite des Yembranes." 
different from the methodical distribution of Crocq's treatise, in which the subject is divided into six sections, on the history, pathological anatomy, etiology, pathological physiology, symptomatology diagnosis and prognosis, treatment. These sections are again formed by subsections and chapters; thus the section on treatment contains a first part, on general therapentics, in fifteen chapters; and a second, on the special treatment of the particular joints, in eight chapters.

Mr. Barwell commences his volume with a chapter on the physiological anatomy of the joints; it contains little to which we need call our reader's attention, and much that might very well have been omitted. One or two points only require notice. The author describes at length the minute structure of the articular lamella, which, he says, is lighter in colour, more transparent than the rest of the bone, does not contain bone-cells or canaliculi, but, "in reality, consists of a series of very minute parallel tubes, which run in a wavy course from the bone to the cartilaginous surface. Among these, but having no special, if any, communication with them, are the bodies mentioned by Kölliker as undeveloped bone-cells." The author considers that these tubes permit the passage of nutrient fluid from the bone to the deep surface of the cartilage.

It has often been questioned whether the articular cartilage is covered by an epithelial layer, a continuation of that covering the synovial membrane. Microscopical examination of sections shows that the appearance of a distinct layer is produced by the cartilagecells gradually becoming flattened and placed horizontally as they approach the free surface. This gradual change is well represented in the figure at p. 12. This structure of the cartilage is urged as a further proof of the source from which the cells derive their nourishment.

"The position of these cells and their gradual separation from each other, and diminution in size, prove that they derive their nutriment from the attached surface, and this is in consonance with the arrangement in other structures which line cavities, for they are all nourished by the deep surface. Thus the absence or presence of vessels upon the fotal cartilage is of importance, because if present it (sic) would establish the fact of a structure lining a cavity being nourished by its free surface. Besides, as it is clear that, at least during intra-uterine life, there is large provision for nutrition of the cartilage from the deep surface, the presence of such vessels would show that a struc. ture having one free, onc attached surface might be nourished from both. Noreover, it would prove that a cellular structure might be nourished from the surface towards which the cells grow. But the two first facts would be isolated, and the last is hardly conceivable; and as others besides myself have lieiled to discover this arrangement, there must have been in the observation of such vessels some occult source of error."

The only other point to be noticed is Mr. Barwell's account of Weber's theory, and of his own experiments. He commences with the statement that "it has been a theory in physiology, that as the synovial membrane is a closed sac, it prevents any admission of air to the inner structures of joints, and forms therefore a vacuum, producing thus a pressure from the exterior which aids materially in keeping 
the joint-surfaces in contact." We know not whence the author has drawn this, as it appears to us, very extraordinary statement; we are afraid that it can neither be received as a representation of what is ordinarily believed, nor yet of Weber's ideas as to this matter. All we believe that he endeavoured to show was that the pressure of the atmosphere played an important part in keeping the bones of the hip and other joints together; that, speaking in general terms, the weight of the limb was supported by the atmosphere, and that thus the muscles and ligaments were relieved from much unnecessary labour. As we think Mr. Barwell has misunderstood the theory, it will not be necessary to discuss his experiments at length. No one imagines that it is impossible to separate the femur from the ilium; the real question is whether greater force will be required to do this than would be necessary if the limb were in vacuo. The experimentum crucis would be to try this with the joint placed in the receiver of an air-pump. Weber, we believe, performed this experiment, and with a result which appeared decisive to him.

The next chapter is on acute synovitis, and on the whole gives a satisfactory account of this disease. A. few of the statements require qualification; thus, that the knee is invariably affected in gonorrhoal rheumatism: such is certainly very often but by no means invariably the case. Rollet, in 28 cases, had only 22 of affection of this joint; Brandes, in 34 cases, 28 ; and Foucart, 14 in 18 cases. The following passage is worthy of notice:

"An old notion fixed, as the first effect of synovitis, dryness of the membrane; and I see, in a recent book on Joint Diseases, that its author, Mr. Bryant, of Guy's Hospital, still adheres to that idea. The theory, however, has no facts to support it, and was supposed to be set at rest by the experiments of M. Richet of the Hôpital Bons-Secours, of M. Bouley, of M. Rey, and of others, none of whom mention dryness as a result of artificially excited and carefully watched synovitis. The first author indeed expressiy denies its existence. He had opened, at different times, the joints of several dogs, and observed hour by hour the alterations taking place in the synovial membrane. He says - 'after ten hours the membrane lost its polish, but I never at any time could find that it was drier than in the normal condition-this dryness of the serous membranes in the first stage of inflammation is admitted by all authors, yet nothing is less proved, and it is to explain their crackling (bruit parcheminé) that this particular condition has been invented.' The first effect, then, of the inflammatory irritation is congestion of the subsynovial tissue, accompanied by rapid secretion of serous or thin synovial fluid into the joint."

The process of granulation, by means of which the synovial membrane becomes gradually thickened, is described at length; it is, according to the author, "precisely similar to that which occurs in a wound healing by the second intention, or in an old abscess which is filling up."

The researches of Dr. R. Volkmannt on the catarrhal forms of pyarthrosis, will necessitate a considerable change in our views as to the production of pus in joints, should they eventually be confirmed.

* J. Rnllet: Recherches sur la Syphilis, \&c., p. 412. Paris, 1861.

$\uparrow$ Langenbeck's Archiv für klinische Chirurgie, Band i. S. 408. Berlin, 1861. 
It has been almost universally admitted, as is of course well known, that pus was not produced in those less severe cases of synovitis which were followed by recovery; secondly, that the pus occasionally found in rheumatic cases, \&c., was the result of unusually violent inflammation; and lastly, that pus once formed in a joint was rarely absorbed, that it was almost always discharged externally. All these assertions will require modification, for he proves that pus may occur in the slighter forms of synovitis, rheumatic, gonorrhœal, \&c., and that it is in many cases readily absorbed. In short, he endeavours to show that there are two kinds of suppuration in joints-a superficial, less violent form, somewhat resembling the catarrhal inflammation of a mucous surface; and a parenchymatous variety, affecting the deeper layers of connective-tissue, accompanied or followed by ulceration, destruction of the cartilages, formation of abscess and of granulations, \&c. After describing the pathology of suppurative synovitis, $\mathrm{Mr}$. Barwell proceeds to consider the symptoms of synovitis in general, and then specially the position and swelling in each joint. As to the diagnosis of inflamed bursæ about the hip, they may generally be recognised by the absence of any alteration in the apparent length of the limb, by the absence of pain on striking the trochanter or the foot, and by the swelling being limited to the region of the bursa. The assertion, that when in synovitis of the knee the secretion is rather large in quantity it causes fulness of the popliteal space, seems to us very doubtful. At the back of the joint the ligaments are the strongest, and there is such a thickness of soft parts that any perceptible swelling does not appear probable. In the treatment we find mention of subcutaneous incision of the synovial membrane, but not of puncture of the joint with a trocar, a method which has been employed and strongly recommended for particular cases by Volkmann in the paper just quoted. Case 7, incised wound of the knee, would have been better treated by ice, for, as the author says in the next page, "locally, ice, or at least very cold water constantly renewed, is the very best application." Some excellent cases of wounds of the knee were published in the 'British Medical Journal' two or three years ago by Mr. Humphreys, of Cambridge; and it is difficult to understand the stupid adherence to a routine system of dressing accidents which prevents so many surgeons from appreciating the extreme importance of this treatment with ice. The publication by the New Sydenham Society of Dr. Montgomery's translation of Esmarch's essay will, it is to be hoped, induce some to abandon the use of poultices, \&c., in recent injuries.

The third chapter is on acute rheumatism, and is almost entirely devoted to showing that the rheumatic affection of joints is a genuine inflammatory disease; the greater part of the fourteen pages thus employed might have been well omitted.

The succeeding chapter commences with a long dissertation on pyæmia, its symptoms, pathology, \&c., which is certainly quite out of place in a treatise on diseases of the joints, and which unfortunately only ends in rather negative conclusions. There then comes a short 
sketch of the local symptoms of pyarthrosis, in which we find it maintained that in gonorrhœal rheumatism the case often does not advance to the actual formation of pus, a statement which will require alteration, for, on the one hand, Volkmann* has shown that pus-cells in small quantity are produced; whilst, on the other hand, it might almost be asserted that abscess never occurs, Velpeau, Foucart, Bonnet, Brandes, and Rollet all agreeing in this opinion. The joints in this disease are occasionally red, and not always extremely white, as stated hy Mr. Barwell.

As to the abscesses occurring in pyæmia, the author recommends-

"Not to open them while the patient's health continues in a very low depressed state, unless absolutely necessary. I have seen the bad symptoms greatly increase after such an operation. The pus in them is often in a very peculiar state, and the least admission of air causes rapid putrefaction. If an abscess must, however, be opened, the wound should be closed as soon as the pus has ceased flowing, and pressure by means of a bandage is to be applied. When, however, the pus is in a joint cavity, the earliest possible opportunity which the condition of health permits should be taken to evacuate the matter by a wide incision in the most depending part. Chlorinated soda lotion upon lint may be inserted into the wound, or indeed, the cavity may be rinsed every day with that fluid by means of a gum-elastic tube and syringe."

Towards the end of this chapter there are a few further remarks on gonorrhœal rheumatism, which is considered by the author to be really "a slower form than ordinary of purulent infection produced by inflammation of the prostatic veins," a view which is, perhaps, worthy of consideration, but which, we are inclined to think, will not prove correct; the comnexion of this form of synovitis with a peculiar form of iritis, + is alone sufficient to cause us to feel some doubt, and we cannot say that we are prejudiced in its favour by the author's further statement, that he has " no cases of dissection to prove this position; persons do not die under gonorrhœal rheumatism."

Strumous synovitis is the disease next considered. Under this denomination we find that form of synovitis described in which there is a peculiar thickening of the synovial membrane by a gelatinous, soft, pulpy material, of a light brown or rose colour, proceeding from both sides of that membrane, and sometimes developed to such an extent as almost entirely to fill the cavity of the joint : pus also is not unfrequently produced in more or less abundance. The newly formed granulations would, in a healthy individual, soon pass on to a further development, that into fibrous or imperfect areolar tissue; whilst in a typical case of strumous joint disease they will continue in the same state without forming fibres, and never advancing beyond their first crude condition. The cartilages and bones ultimately become involved, and the case may then serve as a typical example of the "white

\section{* Loc. cit.}

+ Rollet has devoted an interesting chapter to iritis considered as one of the mauis festations of gonorrhœal rheumatism, loc. cit. p. 393 ; and Mr. Wordsworth has re 2 cently published a paper on the subject in the Ophthalmic Hospital Reports, vol. iii, p. 301 . 
swelling" in its worst form. All these various processes are described satisfactorily by the anthor, without the addition of any new information of importance; the structure of the tissue which was formerly called fungous or lardaceous, was clearly explained many years ago by Lebert, in his treatise 'On Scrofulous and Tuberculous Diseases.' Crocq also has entered fully into this question; even Sir Benjamin Brodie, relying apparently on clinical observation, ultimately arrived at a correct conclusion.

The two forms of scrofula described by $\mathrm{Mr}$. Barwell, would, perhaps, be better entirely separated, as indeed appears now to be the tendency ; for the sake of comparison, we append the characters given by Dr. Jenner :*

Tuberculosis (as signifying the condition of the system in which there is a tendency to the deposit or formation of tubercle).Nervous system highly developed ; mind and body active; figure slim: adipose tissue small in quantity; organization generally delicate ; skin thin; complexion clear; superficial veins distinct; blush ready; eyes bright, pupils long, eyelashes long; hair silken; face oval, goorllooking; ends of long bones small, shafts thin and rigid; limbs straight. Children the subjects of tuberculosis usually cut their teeth, run alone, and talk early.

Leading pathological tendencies.-Fatty degeneration of liver and kidneys ; deposits or formations of tubercle, and their consequences; inflammation of the serous membranes.

scrofulosis. - Temperament phlegmatic ; mind and body lethargic; figure heavy; skin thick and opaque; complexion dull, pasty-looking ; upper lip and alæ of nose thick; nostrils expanded ; face plain ; lymphatic glands perceptible to touch; abdomen full; ends of the longr bones rather large; shafts thick.

Leading pathological tendencies.-Inflammation of the mucous membranes of a peculiar kind ; so-called strumous ophthalmia ; inflamm:tion of the tarsi ; catarrhal inflammations of the mucous membrane of the nose, pharynx, bronchi, stomach, and intestines ; inflammation and suppuration of the lymphatic glands on trifling irritation; obstinate diseases of the skin; caries of bone.

It is curious to observe how the term scrofula has gradually changed its meaning; it was originally employed to designate the various enlargements of the lymphatic glands, which now, according to Lebert, should almost always be considered as tubercular; it was not till the latter part of the last century that it was used in a more extended signification to include a number of affections of the bones, skin, eyes, \&c., which were supposed to be closely allied to the glandular enlargements; since that period it has been applied by different writers in very different senses, and generally very loosely, either as denoting a peculiar constitution, or as a generic name for a number of diseases which had certain appearances in common, or as quite synonymous with tuberculosis; the adjective scrofulous has even had a wider range, 
having been commonly used in a most vague and indefinite manner to denote any chronic inflammation of a joint, of the eyes, \&c., with little or no tendency to recovery. More recently the writings of such men as Milcent,* Lebert, $\uparrow$ Jenner, have diffused some knowledge of the fact that there are many and important differences between scrofulous and tubercular disease, and that a more definite signification may be given to scrofula. Although Mr. Barwell has clearly perceived that these two forms are distinct, and has especially noticed the difference in the treatment, as we shall soon see, he has failed to recognise how. utterly fallacious are many of the characters which he has given. Lebert+ says, in reference to a very similar description of scrofula by Hufeland :- "Les hommes sérieux qui se sont occupés de ces maladies, ne peuvent voir dans cette description pittoresque que de la poésie et du roman, et ces lignes ne témoignent guère d'une expérience médicale de cinquante années de pratique." The same author proceeds thus-

"This picture is, first of all, very much overdrawn; there is especially a sin gular medley of purely accidental features and of characteristics possessing a greater value, such as the thickening of the upper lip and of the nose, the bloating of the face, the enlargement of the submaxillary region, \&c.; but this external aspect is the exception in scrofulous cases, and not the rule; we find it at least in as great a proportion amongst persons affected with tuberculisation of the external glands, without any scrofulous complication. We have also many times observed the same appearances in cretins, who were neither scrofulous nor tubercular; and if we analyze our own statistics of the scrofulous, strictly so-called, we find from our notes that in 537 cases only 81 presented the appearances designated under the title of the scrofulous habitus, 36 of these were males, 45 females, and we have included in the number of 81, 18 persons who had at the same time glandular tubercles. It follows from this analysis, that only in rather more than 1 in 7 of the cases do we observe this pe. culiar external appearance, which therefore loses all pathognomonic value."

And, again, the same author says-

"We have quite as often had undeniable proofs of scrofula and of tubercles in dark-complexioned as in fair persons, in those with finely chiselled features as in those with the face broad and flat, in the quick and lively as well as in the dull and lethargic. The complexion was tolerably often brown, sometimes it was very white and very delicate, but generally there was nothing very striking in its appearance. As to the colour of the hair and eyes, we found an almost equal number amongst the dark, the light, and those with medium shades. Nothing, therefore, in the present state of science, proves that the temperament has any influence as to the predisposition to scrofula and tubercle."

Mr. Barwell recommends in "that form of scrofulous disease which is marked by thick unwieldy connective tissues," genuine scrofula, a purge of calomel and jalap, or of calomel with rhubarb; such a purgative may require repetition once or twice. Sinall alterative doses of mercury may be given for a day or two with advantage; the iodide of potassium is specially indicated. "Quinine, mineral acids, and bitters,

* De la Scrofule, de ses formes, \&c. Paris, 1846.

† Traité pratique des maladies scrofuleuses et tuberrculenses. Paris, 1849. ¥ Loc. cit. p. 65 . 
are the tonics most beneficial. . . . . Iron is far less valuable, and codliver oil very frequently disagrees."

"The form of struma which is distinguished for the fine delicate formation of the connective tissues, is to be managed on a different plan. Purges and mercury in any form must be avoided; the inaction of the intestinal canal is to be combated by mild vegetable aperients; rhubarb given in pill immediately before or with the last meal at night, is an excellent plan, and anything like a violent or irritating evacuant does harm. Iodide of potass in the most typical cases of this sort of struma is not beneficial; the whole class of alteratives are not needed. On the other hand, tonics are extremely valuable. Cod-liver oil is especially indicated, as we desire increase of nutriment; in these cases it very seldom indeed disagrees. Quinine, if the appetite fail, is useful; but iron is to be much more highly prized; in fact, I esteem steel and the oil as the best medicinal agents."

Three stages of the joint-disease are pointed out: 1st, the inflammatory and granulating processes; $2 \mathrm{nd}$, the cartilaginous and osseous inflammation; 3rd, the consolidating and degenerative processes, separately or in combination; and the symptoms then follow. The pain produced by pressing the bony surfaces of the joint together, and which used to be attributed to ulceration of the cartilages, is considered by the anthor to indicate that the articular lamella has given way, and that some of the cancelli are laid bare; this pain had been already attributed by Sir B. Brodie, and we think by others, to disease of the bone. The actual cautery is strongly recommended when the first symptoms of inflammation have somewhat subsided. When the joint has become quiescent, when there is no longer pain on pressure, passive motion, shampooing, \&c., are very useful; they are contra-indicated by "an active condition of the swelling evidenced by pain and tenderness, any considerable amount of degeneration or suppuration, starting pains, and tenderness of the joint surfaces." Ankylosis may be prevented by a judicious use of passive motion; perhaps in only one case should it be intentionally promoted, that case being when the disease has been so extensive, the ligaments so relaxed or destroyed, that the limb would otherwise not support the weight of the body. With Mr. Barwell's concluding sentence we most cordially agree:

"The experience which I have had of the fungous form of strumous disease, and the efficacy of well-adapted treatment, convinces me that extensive suppuration and utter loss of health are the only reasons which should cause us to remove the part. The mere presence of sluggish granulations, evidenced by intractable and long-persistent tumefaction, is no valid cause for such an operation. All such tissue may be made to consolidate or to be absorbed by the adoption of fitting means."

An admirable sentence. Time, good air and diet, careful treatment, will work wonders in the hands of a genuine surgeon.

Chapter VI. is on chronic rheumatic synovitis, which is distinguished from the strumous by the great tendency of the newly-formed granulations to become organized: the synovial membrane is transformed into a tough, firm tissue of a light reddish-brown hue; anchylosis is produced by broad new growths of bone, and thus quite differs 
from that occurring in scrofulous cases, where the bones seem to sink into one another.

In the succeeding chapter we find syphilitic and gouty synoviti; described; then follow chapters on hydrarthrosis, on loose cartilages in the joints, and on acute articular osteitis; there comes next an article on strumous articular osteitis, perhaps the best in the book. Mr. Barwell is not aware of any observations of crude tubercle in bone; he will find several such in Lebert's work, from which we have already quoted; the presence of lime in pus from bone has been determined long since.

The symptoms by means of which strumous articular osteitis may be distinguished from strumous synovitis are tabulated. We should gladly have inserted this comparative sketch, had space allowed. After attending to the general rules of hygiene and constitutional treatment, the most important point is to place the limb in a good position; this may be effected gradually by a splint provided with a screw, or forcibly under chloroform; in many cases subcutaneous tenotomy will be very useful. In some rarer cases tenotomy may be called for, with the view of simply relieving the starting pains, even when the limb is quite straight. The author has hitherto had no case in which he has found such a proceeding necessary; such a treatment has been employed by Dr. Bauer, of New York, who has given a most favourable report of its efficacy.

Chronic rheumatic osteitis follows, and is apparently so called be. cause the author believes it commences with osteitis. Prof. C. O. Weber, * however, in an interesting paper, has endeavoured to show that the earliest changes in this disease occur in the cartilage.

On the inflammation and degeneration of cartilages, the author commences with a short account of the researches of Sir B. Brodie, Goodsir, Redfern, \&c., but does not refer to Virchow, who first really showed these changes to be inflammatory; for although Goodsir, Bowman, and Redfern, by their investigations into the diseases of non-vascular parts, cornea, cartilage, \&c., had pointed out many of the changes, still the ideas of inflammation at that time current were so firmly bound up in vascularity and exudation, that these alterations could not be recognised as truly of an inflammatory nature; Virchow distinguished one form of inflammation in kidney, muscle, and walls of the vessels as parenchymatous, depending on changes in the tissues themselves, and unaccompanied by exudation; and he soon extended this doctrine to the non-vascular parts, such as cartilage. Mr. Barwell says: "I believe myself to have been the first to have pointed out that those diseases of cartilage which accompany the inflammation of other tissues in the joint are in reality inflammation." Our previous remarks show that we believe Virchow really deserves the credit. Prof. C. O. Webert also published, in January, 1858, a very elaborate paper-one in some respects more full than Mr. Barwell's account.

* Virchow's Archiv, Band xiii. S. 82-87. Berlin, 1858.

† Ueber die Veränderungen der Knorpel in Gelenkkrankheiten: Virchow's Archiv, Band xiii. S. 74 . 
However, although we cannot allow the claim of priority, we are quite willing to admit that the author's account is in many respects very careful and satisfactory.

The chapter on disease of the hip-joint is rather deficient; the diagnosis from other affections, such as caries of the ilium, disease of the sacro-iliac articulation, \&c., should have been carefully explained; even the diseases which but rarely simulate it should have been mentioned.* Much valuable information on these points will be found in the works of Crocq and Lebert, and in a lecture on sacro-iliac disease by Mr. Erichsen, recently published in the 'Lancet.'

The next two chapters, on bursæ, synovial sheaths, and the so-called hysterical joint diseases, contain nothing to which we need call attention: in the following one, "On the Restoration of Mobility and Conformity to Crippled Joints," the assertion that Dieffenbach employed sudden and forcible ruptures without tenotomy is incorrect, as may be seen by a reference to his work on operative surgery. Many instructive observations occur in this chapter; for one only have we room. Mr. Barwell is considering the amount of force permissible to break down ankyloses. "The use of considerable force is justifiable for the reduction of a malposture of the knee-joint, but unjustifiable for the reestablishment of mobility in a joint already in a good position."

The last portion of this work is on the removal of diseased joints, and contains a good deal of excellent advice: the great principle is, not to excise or amputate till nothing else can be done-ferrum est ultima ratio. As regards the choice between these two methods of operation, if there shonld be any doubt, the surgeon can commence with excision and end with amputation, should it prove necessary. The author says of the appearances presented by the section of bone:

"These may deviate from the norm by hyperæmia, extravasation, granulation, suppuration, and by wasting or induration of the cancellar walls. This last appearance is in all instances favourable to excision, in direct proportion to the amount of tissue thus affected, in contrast to the amount which has undergone softening; it is a sign of a constitution capable of a sthenic inflammation; such condition is very rarely spread over the whole section surface, and then only in the rheumatic form of inflammation. In strumous cases, induration of the bone tissue, when present, alternates with softened portions, and the more of the thickened tissue be found upon section, the more favourable is the case. Other appearances, hyperæmia, granulation, suppuration, and wasting of the cancellar walls, will all be present in cases of strumous disease so far adranced as to justify operative interference; none of these should of themselves militate against completing the excision; but if they be diffused over the whole, or nearly the whole section, be hardly at all intermingled with indurated portions, and not confined to one or two spots surrounded by thickened osseous tissue, it will be better to amputate the limb. A diffuse inflammation, wherever it be situated, and whatever be its products, always marks so low a constitutional state, that we should give the system as little reparative labour as possible; the granulation produced by

* A case is recorded in the 'Medical Times and Gazette,' new series, vol. viii. p. 317 , where some enlarged and tender glands in the groin apparently were the cause of pain in the hip, limping, flattening of the buttock, \&c.; and another case in the 'London Medical Gazette,' vol. xii. p. 127, where periostitis of the trcchanter simulated morbus coxarius: such cases deserve some notice. 
such an inflammatory act will hardly form the sound tissue so essential to success in these cases, but will greatly tend to the degenerative processes. The more straw-coloured be this tissue, the less should we trust to its organizing force. Again, if the section surface be throughout of a dirty yellow, from diffuse suppuration, and the cancellar walls be all softened, impressable with the finger, or incisable with the knife, amputation should be at once employed. If such appearances be limited to circumscribed portions of the section surface, there is still a further investigation to be made, namely, the depth to which the softening extends. Unless the supcrficies of such a portion be very soft, it is hardly likely to extend far; the gouge, or Mr. Marshall's osteotrite, may be used, and the diseased portions removed; but if they run a long way into the bone, more especially if, as sometimes happens, the several spots unite, and form a large space of softened tissue some way from the surface, the case is not suitable for excision."

In short, the inflammatory changes should be limited to the surface, or little more than the surface, of the articular extremity, and some tendency towards reparation should be exhibited. The different methods of performing excision, and pretty full details of the statistics, are given for each special joint. One case of excision of the knee on a female has been often asserted to have died of tetanus; she did not: the operation was performed by Mulder, a professor at Gröningen, and she ultimately perished from long-continued suppuration, hectic, and exhaustion.

In the note on excisions of the knee performed by German surgeons, there are some errors: Textor, sen., had 4 cases, of which 2 died, and 1 was amputated a year later (operation de complaisance); Textor, jun., 2 cases, both died; Fricke, 3 cases, 2 deaths, 1 recovery; Demme in Bern, 2 successful cases; Brums, 3, of which 2 were successful (probably before 1850); Roser, 2, 1 death, 1 amputation; Prof. Güuther, 1 in 1845, death; Heyfelder, 1, in 1849, death. As to the statistics of amputation, those of the Devon and Exeter Hospital, published by Mr. James,* give a better result than those of Guy's Hospital, at which Mr. Barwell expresses surprise; at the former hospital, there were from 1816 to 1849,118 amputations of the thigh for disease, of which 11 died (=9.322 per cent.); at the same hospital the mortality for all amputations of the thigh $=16.438$ per cent., and for injuries alone $=46.428$ per cent.

The method of excising the ankle-joint recommended by Mr. S. Buchanant seems a great improvement in comparison with the older plan described by Mr. Barwell.

To conclude this somewhat fragmentary analysis, we may say that whilst, on the one hand, we consider that the arrangement of this work is on the whole not good, the author's style diffuse, the language not always grammatically correct, and that scarcely sufficient attention has been paid to the literature of the subject; on the other hand, we are glad to admit that the matter is almost always excellent, and that it will form a valuable addition to English medical literature.

* Transactions of the Provincial Medical and Surgical Association, vol. xvii. p. 52.

+ Glasgow Medical Journal, vol. ii. p. 1. Glasgow, 1855. 